\title{
Molecular abnormalities and cellular signaling pathways alterations in lung cancer
}

\author{
Nikolaos Andreas Chrysanthakopoulos ${ }^{1 *}$ and Nikolitsa S Dareioti \\ ${ }^{1}$ Department of Pathological Anatomy, Medical School, University of Athens, Patra, Greece \\ ${ }^{2}$ Department of Maxillofacial and Oral Surgery, 401 General Military Hospital of Athens, Athens, Greece \\ ${ }^{3}$ Medical Doctor (MD), Department of General Pathology, General Hospital of Patras 'Saint Andrew', Patras, Greece
}

\begin{abstract}
Lung cancer is the main cause of death worldwide despite the progress in surgical treatment, radiotherapy, chemotherapy and targeted therapy. It is accepted that the pathogenesis of cancer involves the accumulation of multiple molecular abnormalities over time that lead to acquired cell capabilities that can be categorized into the following functional groups: self-sufficiency in growth signals due to mutations in proto-oncogenes, insensitivity to anti-growth signals as a result of mutations affecting the tumor suppressor genes, inflammatory micro-environment, evading apoptosis due to up-regulation of anti-apoptotic or down-regulation of pre-apoptotic molecules, limitless replicative potential due to telomerase activation, sustained angiogenesis, tissue invasion and metastasis. Developments in molecular biology and genetics and the modern technology of microarrays have contributed to clarify the aetiology and pathogenesis of lung cancer and a great amount of studies showed more than 20 different genetic and epigenetic alterations that have been accumulated during the pathogenesis of the disease. The above alterations that lead to the accumulation of mutations are promoted by genomic instability through inhibition of apoptosis and alternative pathways.
\end{abstract}

\section{Introduction}

Two major types of lung cancer (LC) have been recorded, the small cell LC (SCLC) that is more rare with faster growth and more frequent development of metastases that already have been existed during the diagnosis procedure and the non-small cell LC (NSCLC) that is more common, whereas it has slow development. NSCLC is distinguished in squamous cell carcinoma, large cell carcinoma, adenocarcinoma (AC) (including broncho-alveolar carcinoma), adenosquamous and sarcomatoid carcinoma. LC histological types, squamous cell carcinoma, undifferentiated SCLC, undifferentiated large cell carcinoma, AC and adenosquamous, are also known as "bronchogenic cancer" or "bronchial carcinoma". This type is the most common and most deaths are caused by it [1]. Pathogenesis of the disease can be attributed to the accumulation of multiple molecular aberrations with the passing of time. Those molecular abnormalities lead to acquired cellularity capabilities that can be categorized into the following functional groups: self- sufficiency in growth signals due to mutations in proto-oncogenes, insensitivity to anti-growth signals as a result of mutations affecting the tumor suppressor genes, inflammatory microenvironment, evading apoptosis due to up-regulation of anti-apoptotic or down-regulation of pre-apoptotic molecules, limitless replicative potential due to telomerase activation, sustained angiogenesis, tissue invasion and metastasis [2].

\section{Lung cancer molecular biology}

Cigarette smoking accounts for about $85 \%$ of NSCLC cases and $98 \%$ of SCLC cases. Tobacco smoke contains more than 7,000 chemicals including over 70 known carcinogens that cause cancer such as nitrosamine ketones and polycyclic aromatic hydrocarbons (PAH) that are responsible for the genetic mutations due to the formation of a complex with DNA. That formation is induced by activation of the mentioned carcinogens metabolism, by metabolism of the above carcinogens by cytochrome P450, CYP family enzymes and glutathioneS-transferases (GSTs). In many LC signaling pathways the functions of the mentioned enzymes have been changed. Most of them are regulated by oncogenes that lead the cells to a malignant phenotype, uncontrolled proliferation and evasion of apoptosis [3].

The mentioned molecular changes concern oncogenes and tumor suppressor genes and can be occurred at the level of upstream or downstream gene regulation, due to changes in DNA sequence (point mutations), loss of heterozygosity (LOH), amplification of DNA segment or the loss or gain of an entire chromosome with a concomitant gene instability and changes in micro- satellite DNA [4,5]. Developments in Molecular Biology and Genetics as well as the modern Microarray technology have contributed to clarify the LC pathogenesis and a great amount of investigations have shown more than 20 different genetic and epigenetic alterations to be accumulated during the pathogenesis of LC as a clonal multistage process. The above conditions that lead to accumulation of mutations are promoted by genomic instability through inhibition of apoptosis and alternative pathways [6-8].

The most explored changes till now, are the inactivating mutations and loss of tumor suppressor genes and overexpression of oncogenes that induce tumor growth. Recently, it was observed the epigenetic inactivation of tumor suppressor genes due to promoter hypermethylation. Early clonal genetic abnormalities that are observed

*Correspondence to: Nikolaos Andreas Chrysanthakopoulos, 35, Zaimi Street, PC 26 223, Patra, Greece, Tel: 0030-2610-225288; E-mail: nikolaos_c@hotmail.com, nchrysant@med.uoa.gr

Key words: lung cancer, epidemiology, molecular biology, adults

Received: August 10, 2018; Accepted: August 27, 2018; Published: August 31, 2018 
in pre-tumor bronchial epithelium that is damaged by smoking or several carcinogens have also been identified. Similarly, molecular differences have been described between SCLC and NSCLC cases and among tumors that are characterized by different clinical outcomes [9].

In SCLC patients, various tyrosine kinase receptors are overexpressed and involved in cell proliferation, migration and survival through alterations of the reactive oxygen species (ROS) and activation of downstream signal transduction molecules [10]. In addition, multiple chromosomes abnormalities that reflect genetic instability have been found in SCLC patients and in patients that suffer from other epithelial tumors. The majority of SCLC patients have shown deletions of multiple chromosome sites with specific losses on $3 p, 5 q, 13 q$ and $17 \mathrm{p}$ that contain tumor suppressor genes including p53. Analyses of comparative genomic hybridization have recorded a great number of the underlying gains in SCLC patients at regions $1 p, 2 p, 9 p, 5 p, 8 q$ and $19 \mathrm{p}$. Those regions are responsible for encoding known oncogenes such as Myc and K Ras. SCLC cell lines showed amplification on 1p, 2p and $3 q$, with deletions of $18 \mathrm{q}$ and were associated with a more aggressive phenotype of the disease [11].

Chromosome $3 p$ allele loss is a frequent event in $90 \%$ of SCLC patients and is considered an early event in LC pathogenesis [12]. Other loss regions that have been identified include the following regions 3p21.3,3p12, 3p14.2 and 3p24 [10]. Various genes in those loci play a role in tumor suppressive action and often lose their expression through epigenetic mechanisms. The tumor suppressor genes on the region 3p21 include RASSF1A, FUS1, SEMA3B and SEMA3F, whereas the FHIT (fragile histidine triade) gene is located at 3p14.2 locus, the region 3 p 24 contains the RAR $\beta$ gene and all have an essential role in LC pathogenesis [13].

\section{Oncogenes stimulate cell growth}

Protein tyrosine kinases (PTKs) are vital intracellular signal transduction pathways regulators that mediate cellular growth and 'cell-to-cell' communication. Their action is normally controlled and regulated. Disturbances in signaling of PTKs derived from mutations and other genetic alterations contribute to the malignant transformation. A number of growth factors and their receptors are expressed by LC cells or the adjacent stromal cells and produce autocrine or paracrine growth stimulation loops that are encoded by proto-oncogenes and can be activated during the development of LC [9].

The overexpression of cell cycle protein regulators such as Cyclin D1 [14], Cyclin E [15] and Cyclin B1 [16], enhance cell proliferation, reduce potential of cell apoptosis, and are often found in NSCLC histological samples [9].

The epidermal growth factor receptor (EGFR), known as ErbB-1, is a member of a family of closely related proteins. EGFR belongs to the family of receptors with tyrosine kinase activity (RTKs), known as HER/ErbB family and consists of 4 known receptors: EGFR or HER1-4/ErbB1-4. Its activation by appropriate ligands, such as EFG, amphiregulin, heparin binding EGF, etc., results in the activation of the receptor's intracellular tyrosine kinase domain which undergoes autophosphorylation and can trigger a cascade of intracellular events. In particular, it leads directly to the activation of important intracellular signaling pathways such as Ras-Raf kinase (MEK), MAPK-kinase, Akt-RT3K kinase and mTOR-protein. The Ras-Raf-MEK-MAPK pathway regulates several cellular processes such as transcription, cell cycle progression at the G2/S phase and cell proliferation, whereas the PI3K pathway regulates anti-apoptotic mechanisms. EGFR is able to activate more pathways such as the STAT proteins and protein kinase
C pathways, however, the effect of EGFR on the molecular level has not yet fully defined. In $50-80 \%$ of NSCLC cases it has been found that either the EGFR is overexpressed or an increased activity in the EGFR pathway activation has been found that can be attributed to the following mechanisms:

A. Increased protein levels of the receptor in the cancer cell membrane, with or without corresponding increase in levels of gene expression,

B. EGFR mutations that can result in continuous activation without the presence of the proper ligand,

C. Increased levels of proper ligands such as EGF or TFG- $\alpha$ (transforming growth factor alpha) [17].

The signaling pathway that is regulated by those receptors is complex and any disruption in its activation leads to processes that can induce carcinogenesis. Such processes are the inhibition of apoptosis, uncontrolled cell proliferation, insensitivity to anti-growth signals, angiogenesis, tissue infiltration and metastasis [18].

Another study showed that over-expression of EGFR was observed in $62 \%$ of NSCLC cases and it was often associated with poor prognosis and resistance to chemotherapeutic agents including cisplatin [19]. Deregulation of the EGFR signaling-pathway is observed in many types of cancer, whereas SCLC consists one of the solid tumors in which no overexpression of that receptor was observed. The HER-2/ neu (ErbB-2) gene is located on chromosome $17 \mathrm{p} 21$ and encodes for a transmembrane glycoprotein (p185HER-2/neu) that is highly homologous to EGFR. HER-2/neu is overexpressed in approximately $30 \%$ of NSCLC cases, particularly in AC and is associated with multidrug resistance phenotype and a higher rate of metastases [9]. A point mutation that leads to substitution of a glutamic acid (Glu) for a valine (Val) at position 664 is usually found and contributes to malignant cell transformation. Alterations and amplifications of the HER-2/neu gene have been reported in NSCLC cases [18].

The Myc gene family encodes nuclear DNA binding proteins, c-, Nand L-Myc that function as transcription factors and thus regulate the cell proliferation, apoptosis and differentiation [20]. Those genes exhibit amplification in $15-30 \%$ of SCLC cases and in less rate in NSCLC cases $[3,21]$. Protein overexpression has been observed in SCLC cases due to $\mathrm{Myc}$, activation that caused by gene amplification or transcriptional deregulation [22], which has been found in 18-31\% of NSCL cases [23] and is associated with reduced survival [10]. Myc phosphoproteins are located at the cell nucleus [24] and their transcriptional regulation is mediated by hetero- dimerization with proteins such as MAX, MAD or MX11 [25]. The Myc-MAX heterodimer binds to specific DNA sequences that are known as E-box elements in adjacent region of downstream target-gene and activates their transcription. On the other hand, the Myc-MAX complex suppresses the transcriptional activation. MAX has been found to interact with at least two proteins, MAD and MXI1leading to the transcription suppression, antagonizes Myc function and promotes cell differentiation [18]. The molecular abnormalities that are involved in Myc genes or their transcriptional deregulation were found to be significant molecular mechanisms in the pathogenesis of LC [15].

Gene amplification or gene-overexpression without amplification consist the most common abnormalities that involves Myc members in LC. Overexpression of c-Myc gene, with or without amplification, was found in $80-90 \%$ of SCLC cases, whereas the amplification of it is only found in $10 \%$ of NSCLC samples. However, the overexpression of c-Myc gene without its amplification has been found in more than $50 \%$ 
of NSCLC samples. c-Myc gene overexpression has been found to be a delayed event in LC pathogenesis in the majority of SCLC patients [24]. Cell lines derived from metastatic tumors showed a high incidence of c-Myc amplification and that finding may explain the relationship between c-Myc amplification and poor clinical prognosis [26].

The dominant RAS proto-oncogene is extremely important for signal transduction that promotes the cell proliferation. The RAS oncogene family includes the HRAS, KRAS 2 and NRAS genes, and consists a part of the signal transduction SOS-Ras-Raf-MAPK mitogenic cascade [2]. In malignant cells the point mutation in the RAS gene is able to make the RAS protein deficient regarding its inherent GTPase activity so that it is locked in the stimulated form continuously and sends signals that are able to stimulate cell proliferation in the nucleus [27].

Ras mutations are rare or absent in SCLC cases, however they can be found in $15-20 \%$ of NSCLC cases. Approximately $50 \%$ of the AC's show RAS mutations [28], and usually affect the KRAS codon 12, in $85 \%$ of cases, and rarely the HRAS codon 13 or the N RAS codon 61 [25]. The majority, up to $70 \%$ of those mutations are $\mathrm{G} \rightarrow \mathrm{T}$ transformations induced by benzopyrene diethyloxide (BPDE), nitrosamines and other DNA-damaging agents that are contained in cigarette smoke. It is considered that this is the reason for the correlation between smoking history and the frequency of RAS mutations in NSCLC cases that are associated with poor prognosis [29].

Another pathway that is deregulated in LC is the ALK kinase (anaplastic lymphoma kinase fusion proteins), in which a fusion between the EML4 gene (echinoderm microtubule associated protein like 4) and the ALK gene is observed in 7\% of NSCLC cases and this results in the activation of the ALK protein kinase domain. That finding is usually found in never smoked patients and may play a role in activation of the RAS [3,21].

The TTF1 pathway (thyroid transcription factor 1), which consists an important transcription factor that is necessary for the development of peripheral airways, when is inhibited by RNA- interference (RNAi) leads to inhibition of tumor growth and apoptosis [3,21].

\section{Insensitivity to anti-growth signals: abnormalities in tumor suppressors genes}

Tumor suppressor genes play a crucial role in cell anti-proliferative function and also participate in the cellular response to DNA damage and in subsequent redress procedures. A frequent loss of tumor suppressor genes during the LC pathogenesis and progression has been recorded, as well as in many epithelial cancers. Inactivation of tumor suppressor genes could be attributed to genetic or epigenetic mechanisms such as the loss of one allele from a chromosomal site, that is known as $\mathrm{LOH}$ and the inactivation of the second allele is caused by gene mutation or promoter hypermethylation. The most frequently chromosomal regions found to be affected by $\mathrm{LOH}$ in $\mathrm{LC}$ are $1 \mathrm{p}, 3 \mathrm{p}, 4 \mathrm{p}$, 4q, 5q, 8p, 9p (p16 TSG locus), 9q, 10p, 10q, 13q (Rb-locus),15q,17p (p53 locus), 18q, 19p, Xp and Xq3. Chromosome 3p allele loss is one of the most frequent and earlier genetic events in LC pathogenesis and was found in $96 \%$ of cancers cases and $78 \%$ of pre-tumor bronchial epithelial lesions [30]. In previous studies in many cell lines and tumor samples have been observed high rates of $\mathrm{LOH}$ and an increased frequency of homozygous deletions. That observation indicates that few potentially tumor suppressor genes are located in this chromosome region [25]. In addition, the frequency and magnitude of $3 p$ allele loss was associated with the severity of histopathological precancerous/ pre-infiltrative lesions. A number of other candidate tumor suppressor genes are located on chromosome $3 p$ and the loss of their alleles may possibly be the earliest acquired genetic abnormality in the pathogenesis of LC [9,31].

The FHIT gene has been shown to function as a tumor suppressor gene for most human cancer, is located at chromosome 3p14.2 and encodes for a protein called p FHIT. Loss of FHIT causes defective DNA replication, and leads to further DNA breaks. FHIT is specifically targeted and regulates death receptor (DR) genes. Pre-clinical studies have shown that the FHIT wild type infection in LC cells induces apoptosis [32].

Reduced expression of the pFHIT protein has been observed in $49 \%$ of the NSCLC samples, immunohistochemically, whereas homozygous deletions were present in $100 \%$ of the SCLC cases [33]. pFHIT expression is significantly decreased in a large number of earlystage NSCLC cases and in a number of pre-neoplastic lesions in chronic smokers. The relationship between cigarette smoking and expression of the pFHIT suggests a role for the gene and its association with smoking carcinogenesis [18]. It has been shown that the FHIT wild type restoration inhibits LC growth in vitro and tumorigenicity in nude (athymic) rats in vivo [25].

The RAR $\beta$ gene ( $\beta$-receptor of retinoic acid) is located at chromosome 3p24 and consists a candidate tumor suppressor gene. Low RAR $\beta$ expression or a lack of RAR $\beta$ expression, have been reported with high frequency in LC cell lines and primary lung tumors [25]. The mentioned finding appears to be derived from RAR $\beta$ gene promoter abnormal methylation and was observed in $40 \%$ of primary SCLC cases. In another study, it was found that the RAR $\beta$ gene is methylated in $72 \%$ of SCLC cases and leads to the loss of its expression. The RAR $\beta$ gene regulates epithelial cell growth, tumor suppression and oncogenesis [34].

The tumor suppressor gene TP53 (p53) is located on the short arm of the chromosome 17 (17p13.1) and encodes for a nuclear protein that acts as a DNA-bound transcription factor that activates gene expression and is associated with cell cycle arrest in the G1 phase or in cell death in response to genotoxic stress. Its role is to preserve genome integrity by acting as the 'guardian' of the genome during cellular stress caused by DNA damage, hypoxia and activated oncogenes. It also prevents cells with damaged DNA from entering the G2 phase of the cell cycle by inhibition of CDC2 cyclin-dependent kinase that is required to enter mitosis. The ability of p53 to efficiently inhibit cell proliferation or to induce apoptosis can be suppressed by the HDM2 protein, the human homolog of the MDM2 protein. The HDM2 protein blocks the regulation of p53 target genes and enhances its cleavage by the proteasome [35]. On the other hand, p53 upregulates the expression of HDM2 via a direct connection and activation of the HDM2 promoter and thus p53 downregulates its own expression. This self-regulating loop maintains p53 in practically low or undetectable levels in normal cells [2]. The TP53 gene is more frequently mutated than any other gene in human genome and is one of the most significant events in LC. Its mutation is directly related to exposure to carcinogens and especially cigarette smoke $[3,21]$.

Nonsense mutations, mainly $\mathrm{G} \rightarrow \mathrm{T}$ transpositions that are concentrated in the middle of the gene at codons 157, 245, 248 and 273 are able to abolish the activity of this protein as a suppressor protein and extend half-life of p53 mutant protein which can readily be detected immunohistochemically. The p53 gene mutations in LC patients have been extensively investigated and was found that p53 is inactivated in 
$75 \%$ of SCLC cases and in $50 \%$ of NSCLC cases [18,33]. Inactivating mutations have been observed in $90 \%$ of the SCLC cases, most of which are non- sense mutations in the DNA binding domain and a smaller number are homozygous deletions [12]. In 40-70\% of SCLC cases has been recorded an abnormal expression of p53 protein [33], whereas its mutations are related to cigarette smoking, especially the GC $\rightarrow$ TA transformation is caused by carcinogenic benzo(a)pyrene of tobacco [10].

Mutations at codon 157 are unique in LC cases whereas those at codons 248 and 273, especially 'hot spots' mutations, are also present in other cancers, such as in colon, liver and prostate. Non- smokers with LC show a totally different and random grouping of p53 mutations [24]. The tumor suppressor gene $\mathrm{Rb}$ is located at chromosome $13 \mathrm{q} 14$ and its product, a nuclear phosphoprotein was first found in the childhood retinoblastoma. $\mathrm{Rb}$ protein co-operates with $\mathrm{p} 53$ in the cell cycle regulation and control, in the transcriptional level and in the balance between cell differentiation and proliferation. The $\mathrm{Rb}$ protein phosphorylation status and its interaction with the transcription factor E2F play a critical role in the regulation for the G0/G1transition [36].

Abnormalities of the $\mathrm{Rb}$ gene in LC cases include antisense mutations, pathogenic splice variants and chromosome deletions. More than $90 \%$ of SCLC cases and $15-30 \%$ of NSCLC cases show abnormal or non-expression of the $\mathrm{Rb}$ protein [24].

Although the $\mathrm{Rb}$ protein plays an important role in the LC pathogenesis, its status has no prognostic significance in NSCLC patients [18]. The phosphatase and tensin homolog (PTEN) gene is located on chromosome 10q23 and encodes for a lipid phosphatase which dephosphorylates PIP3 and exhibits tumor suppression activity in vitro and in vivo. Mutations or deletions of that gene have been found in a few LC cell lines and tumor samples [25].

The transforming growth factor- $\beta$ (TGF- $\beta$ ) is a multifunctional protein that inhibits the proliferation of most epithelial cells by binding to a great number of cell receptors. It consists an inhibitor-checkpoint that is involved in the cell cycle regulation, prompting the cells to stop their proliferation during the G1-phase of the cell cycle. Reduced expression levels of TGF- $\beta$ were found in NSCLC samples by the use of immunocytochemical methods [24].

Deleted in malignant brain tumors 1 gene (DMBT1) is a candidate tumor suppressor gene that is located at chromosome 10q25-26 and is often downregulated and occasionally homogeneously deleted in LC [25].

P16INK4 (or CDKNA2) is a tumor suppressor gene that is located at chromosome 9p21 and encodes for two proteins that are translated by alternative mRNA splicing, $\alpha$-transcription that is translated into p16 (p16INK4) and $\beta$-transcription that is translated into p14ARFprotein. Loss of p14ARF or $\mathrm{p} 53$, that are common genetic alterations in LC, allows for an accumulation of c-Myc and, therefore, for cell proliferation and transformation. The p14ARF protein appears to bridge the gap between oncogenic signals and p53, according to which the p14ARF-mediated activation would be critical to lead the cell to apoptosis [24, 35].

Expression of p16INK4 gene in NSCLC cases is often altered due to abnormalities of promoter methylation , in $25 \%$ of cases, homozygous deletions or point mutations in $10-40 \%$ [25].

It has been found that the disorders in both pathways, $\mathrm{p} 16 / \mathrm{Rb}$ and $\mathrm{p} 53$, are essential for the enhanced proliferation in NSCLC cell lines. A reverse relationship between p16 and $\mathrm{Rb}$ in $\mathrm{LC}$ has been observed in which the $\mathrm{Rb}$ gene is mutated and p16 gene is intact in SCLC cases, whereas the p16 expression is disrupted and the $\mathrm{Rb}$ gene is usually intact in NSCLC cases [24]. In addition, in SCLC cases, the most common abnormality in the p16INK4A-Cyclin D1-CDK4-Rb pathway that mediates the transition from phase G1 to phase $S$ of the cell cycle concerns the $\mathrm{Rb}$ gene. The types of the $\mathrm{Rb}$ gene mutations include deletions, antisense mutations and splicing abnormalities [37]. Complete loss of the gene or a mutant form of it have been found in more than $90 \%$ of SCLC cases [38].

p19ARF binds to MDM2-p53 and prevents the p53cleavage. Loss of p19ARF is more common in lung tumors with neuroendocrine features [25,35].

Methylation-associated inactivation of RASSF1A gene has been observed in many human malignancies [13]. That gene encodes for a protein similar to RAS effector proteins and is in- activated in more than $90 \%$ of SCLC cases [14]. RASSF1A is also involved in cell cycle path- ways, apoptosis and microtubule stabilization [39].

Loss of FUS1 protein expression has been found in 100\% of SCLC cases [40]. The wild type of the gene induces G1 phase arrest and apoptosis [12].

\section{Evading apoptosis}

Apoptosis or programmed cell death is a genetically controlled process that is essential for the remodeling of tissues during embryogenesis and for maintaining of the homeostatic balance of the number of cells during their function. The deregulation of the cell death pathways is involved in the tumor initiation, development and resistance to treatment in many human cancers and consists one of the main features of cancer $[2,41]$.

Main genes that regulate the apoptosis process are p53 tumor suppressor gene and the $\mathrm{Bcl}-2$ gene family. The members of the $\mathrm{Bcl}-$ 2 family are the main regulators of the apoptotic process whereas caspases are the main effectors $[42,43]$. The Bcl-2 family includes anti(bcl-2, bcl-X, mcl-X) and pro-apoptotic proteins (bax, bak, bad) that regulate the cell death and mechanisms such as apoptosis, necrosis and autophagy [44], whereas alterations in its expression lead to the pathogenesis and progression of malignant neoplasms [45]. BAX protein is associated with Bcl- 2, promotes apoptosis and constitutes a downstream transcriptional target of $\mathrm{p} 53$. The $\mathrm{Bcl}-2$ protein heterodimerizes with BAX and inhibits apoptosis. Tumor cells often escape apoptosis, as a normal physiological response in case those cells are exposed to cellular lesions and lesions in DNA. Anti-apoptotic Bcl2 proteins are typically overexpressed in many malignancies and their expression is often related to drug sensitivity $[46,47]$.

Overexpression of Bcl-2, that is detected by immunohistochemistry, was found in $75-95 \%$ of SCLC cases, in $25-30 \%$ of squamous cell cancers cases and in $10 \%$ of AC cases [48,49]. The significantly higher frequency of $\mathrm{Bcl}-2$ overexpression in SCLC cases is unexpected as these tumors are more sensitive to chemotherapeutic agents that induce an apoptotic response. Interestingly, $\mathrm{BAX}$ and $\mathrm{Bcl}-2$ proteins expression is inversely related to neuroendocrine cancers, whereas high Bcl-2 and low BAX expression have been found in the majority of SCLC cases that appear inadequate in identifying p53 expression [9].

The importance of the Bcl-2 protein expression in LC for overall survival is ambiguous but the $\mathrm{Bcl}-2$ expression was found to be associated with better prognosis in patients with NSCLC that may be associated with a lower level of tumor vascularization $[18,50]$. 
The nuclear factor NF-kB is activated by inflammatory cytokines (TNF- $\alpha$, IL- $1 \beta$, IFN- $\gamma$ ) and bacterial products (LPS), consists an important effector of the inflammatory response and is involved in the evasion of programmed cell death. That factor is activated by the smoke components, whereas it is also activated in epithelial cells and macrophages in Chronic Obstructive Pulmonary Disease (COPD) patients, it shows anti-apoptotic action by interaction with Bcl-2 and $\mathrm{Bcl}$-XI factors and is associated with chronic inflammation, such as COPD, and carcinogenesis of the respiratory tract. Its activation by chemical carcinogens concerns the epithelial cells and macrophages as mentioned, whereas its inhibition leads to a decrease in chemical carcinogenesis by $58 \%$ [51].

\section{Limitless replicative potential due to telomerase activation}

Telomeres are specific chromatin structures at the end of each chromosome that are used as protective caps and play a role in maintaining of their integrity, as are able to suppress reversibly the transcription of adjacent genes and to prevent the 'end-to-end' fusion or the cleavage of the chromosomes [52].

Because of the inability of conventional DNA polymerases to replicate 5 '-terminal of DNA, the telomeres are shortened in normal human somatic cells during cell division, a phenomenon known as a 'end-replication-problem'. That shortening does not lead to loss of essential genes as each chromosome is covered by telomeres. The human telomere consists of highly repetitive sequences (TTAGGG) [53] and it has been estimated that 50-100 bp are lost per cell division cycle [54]. It has also been observed that human cells have a potential to undergo a value of approximately 50-70 divisions. After that limit the cell growth is interrupted and enter a phase of senescence. Telomere maintenance requires complex interactions between proteins, telomeric DNA and other cellular factors. Telomere integrity is also essential for chromosomal stability and telomere shortening facilitates the progression of cancer cells as leads to 'end-to-end' chromosome fusions and aneuploidy development. Telomerase inhibition in immortal cancer cell lines with application of genetic or pharmaceutical methods leads to telomere shortening and ultimately can stop cell proliferation [55].

Telomerase is a ribonucleoprotein enzyme complex that prolongs and maintains chromosome ends- telomeres of the eukaryotic chromosomes using one native RNA molecule as a template and thus extends the number of cell divisions [56]. In other words, it is a RNAdependent-DNA- polymerase that can compensate for the loss of those DNA sequences by synthesizing telomeric replicates in cells that are able to be divided. A catalytic subunit, telomerase reverse transcriptase (hTERT) with the telomerase RNA component (TERC) comprises the most important unit of the telomerase complex [57].

Telomerase activity is absent in most normal cells in adults but increases during tumor growth [58]. In differentiated cells telomerase activity is silent. Cells acquire the immortal phenotype by compensating for loss of telomeric repeat by reactivation of telomerase [59], leading to continuous cell division. Given that more than $90 \%$ of human neoplastic cells show an increased telomerase activity, it is accepted that this is one of the main features of cancer, is quite common and related with the molecular abnormalities in cancer. Telomerase expression in malignant tumors determines the ability for unlimited proliferation and hence the immortality of those cells. High telomerase activity was detected almost $100 \%$ of SCLC cases and $80 \%$ of NSCLC samples using PCR technique. In addition, high telomerase activity in primary NSCLC cases was found to be correlated with elevated cell proliferation rates and advanced pathological stage [60]. It has also been found that more than $98 \%$ of SCLC cases showed upregulation of telomerase activity $[57,61]$.

Recently, shortening of the telomere was found to be an early molecular abnormality in the broncho-epithelial carcinogenesis preceding the expression of telomerase and the inactivation of $\mathrm{p} 53 / \mathrm{Rb}$ that observed in the majority of pre-invasive lesions [62].

Based on the fact that telomerase activity is associated with malignant growth, it can be used as an indicator for LC detection as well as an important target for new therapeutic approaches [25].

\section{Tumor angiogenesis}

The development of new blood vessels, neovascularization, is necessary for tumor development beyond $3,00 \mathrm{~mm}$ in diameter and is critical to the metastatic ability. Different inducers and inhibitors regulate the endothelial cell proliferation and migration as are involved in the process of angiogenesis. Growth factors that have been found to stimulate angiogenesis are the vascular endothelial growth factor (VEGF),the fibroblast growth factor (b FGF), the platelet-derived endothelial cell factor (PDEGF) and the platelet-derived growth factor (PDGF) $[9,25]$.

VEGF is a family of factors that consists of VEGF-A, B, C, D and F factors and VEGFR 1-3 receptors. The VEGF signaling pathway leads to increased proliferation, migration and invasion of endothelial cells, mediating tumor angiogenesis. Autocrine VEGF/VEGFR signaling pathway regulates cell proliferation and metastases development [63].

High levels of VEGF have been found in SCLC patients and were related to the tumor staging, progression, resistance to chemotherapy and poor prognosis. SCLC cells express VEGFR-1 and -2 and are involved in tumor growth and infiltration [64].

The products of angiogenic factors affect the clinical prognosis in LC patients, i.e VEGF plasma levels are related to the degree of vascularization in NSCLC cases, whereas VEGF expression was found to be associated with a decreased overall- and disease-free survival in NSCLC patients [65].

Basic fibroblast growth factor (bFGF or FGF-2) shows a biological role in SCLC cases [64]. Elevated levels of bFGF in the serum of SCLC patients are associated with poor prognosis and active angiogenesis [66]. In addition, bFGF promotes the development of SCLC cells and leads to resistance to chemotherapeutic drugs $[67,68]$. Immunochemical studies have shown that bFGF is a prognostic marker in LC patients as the 5-year survival rate was significantly lower for bFGF positive patients, whereas its aggressive clinical behavior was associated with upregulation of PDGF [25].

\section{Tissue infiltration and metastasis}

The molecular mechanisms that lead the cells of the primary LC to infiltrate the adjacent tissues and spread to remote regions and organs, remain unknown [9]. This process involves de- gradation of the basement membrane, infiltration of the environmental layer, blood or lymphatic vessels, developmental ability without attachment, angiogenesis, cell proliferation and migration [2]. A small number of different genes as well as their protein products have been identified as important for the process of tissue infiltration and the metastatic ability of neoplastic cells. E- Cadherin is a cell adhesion molecule that is expressed mainly by epithelial cells. During the pathogenesis of most epithelial cancers, its 
function is lost by the mutational inactivation of its genes or $\beta$-Catenin genes as well as by the transcriptional suppression or the enhanced proteo- lysis. That process leads to a decreased, E-Cadherin-mediated 'cell-to-cell' adhesion and allows malignant tumor cells to infiltrate the tissues and to enter the blood or lymphatic vessels [69]. Thus, E-Cadherin gene is known as a "infiltration suppressor gene" [70] and it was also found that the loss of E-Cadherin in LC cases was associated with increased metastatic ability [71].

The basement membrane and the extracellular matrix can be degraded by proteases and that process is of a vital importance for local infiltration and vascular or lymphatic metastasis. The matrix metalloproteinases (MMPs) are one of the main families of proteinases and especially are calcium-dependent zinc containing endopeptidases which facilitate infiltration, the ability to metastasize and the tumor-associated angiogenesis. In contrast, inhibitors of matrix metalloproteinases (TIMPS) has been found to inhibit tumor growth and its spreading in pre-clinical models. Therefore it remains unknown why all LC cases do not express MMPs whereas there have been found conflicting options regarding the predictive significance of their expression in LC [72].

It was found that collapsin response mediator protein-1 (CRMP1 ), a protein that can mediate the effect of collapsines, has decreased expression in more aggressive and metastatic LC samples [73]. That down-regulation can enhance the ability of cell migration that is important for the process of metastasis. Those CRMP-proteins and other members of the collapsin/semaphorin proteins family can regulate cell mobility [74].

Laminins and integrins are proteins involved in infiltration of adjacent tissue through the basement membrane and are responsible for LC widespread. The decreased expression of laminin $\alpha$ - chains ( $\alpha 3$ and $\alpha 5$ ) in pulmonary neoplastic tissue can lead to the fragmentation of the basement membrane that is required for the infiltration of cancer cells [75].

Alterations in integrin's expression have been found in metastatic cells in many human neoplasms as well as in LC $[2,76]$. Recently it was found that the LAMB3 gene, that encodes for laminin $\beta 3$ chain, a component of laminin-5, was only expressed in NSCLC cells and not in SCLC cells. In the same study, a6 $\beta 4$ integrin, the specific binding receptor of laminin- 5, was expressed only in NSCLC cells, but not in SCLC cells. This observation suggests that laminin- 5 may be has a critical role in NSCLC development [77].

\section{Tyrosine kinase receptors (RTKs) - growth factors in SCLC}

The c-Kit receptor is a member of the PDGF/c-Kit RTKs family. Following ligand binding, that is a stem cell factor (SCF), cell growth and differentiation begins with the activation of JAK/STAT, PI3K and MAP-kinase pathways [62] and thereby contribute to the pathogenesis of SCLC [78]. c-Kit expression has been found in 79-88\% of the SCLC cell lines, whereas both c- Kit and stem-cell factor (SCF) expressions have been found in $57-76 \%$ of SCLC cell lines [10]. c-Met RTK is activated by its ligand, hepatocyte growth factor/scatter factor (HGF/ $\mathrm{SF}$ ) and activates cationic molecules such as Grb 2 (growth factor receptor-bound protein 2), p85 sub- unit of PI3K, STAT3 and Gab1 (Grb 2-associated binder-1). Overexpression and amplification of c-Met have been found in LC cells, whereas higher levels of HGF are associated with poor prognosis $[10,62]$. HGF/c-Met pathway promotes more aggressive tumor type in SCLC and modulation of c-Met/HGF pathway results in changes in cell mobility and migration $[79,80]$.
IGF-1 receptor (Insulin-like growth factor-1 receptor) is a member of the RTKs superfamily and is activated by IGF-1 and -2 ligands, induces mitogen signal transduction and is associated with antiapoptotic and transformation activities. The IGF-1R receptor and its ligand are expressed at high levels in SCLC cell lines, whereas more than $95 \%$ of SCLC cases, IGF-1 protein levels have been found elevated $[10,62]$. In addition, the IGF-1R receptor activates the PI3K-AKT signaling pathway in SCLC cases and contributes to the development of the disease as well as the resistance to chemotherapy [62]. The fibroblast growth factor receptor (FGFR) is a member of the RTKs family that contains 4 different isoforms (FGFR1-4). Upon binding to fibroblast growth factors (FGFs) the receptor interacts with multiple signaling proteins and activates the Ras/Raf/MEK/Erk 1, 2 and PI3K-AKT signaling pathways [81] (Table 1).

\section{Epigenetic alterations in LC}

The term epigenetic alterations refers to molecular mechanisms that regulate gene expression without alteration in the DNA sequence and includes histone modification and DNA methylation that is the main epigenetic mechanism. DNA methylation is essential for normal development and gene regulation. In the pathogenesis of cancer may play a critical role 3 forms of abnormal methylation, namely hypermethylation of tumor suppressor genes, hypomethylation and the fact that methylation can regulate the expression of some microRNAs (mi-RNAs). In LC patients, it was found that many genes are not expressed due to methylation of the primer. Methylation is an early event in LC pathogenesis and its detection in the sputum of patients with dysplasia can be considered as a high-risk indicator for the appearance of the disease. In addition, detection of DNA methylation may be a prognostic factor for early recurrence in NSCLC stage 1 [82].

Another molecular mechanism are mi-RNAs, a small non-coding RNA molecule that it contains about 22 nucleotides and regulate gene expression as is involved in activity of specific mi-RNA targets by interactions among bases. Many mi-RNAs have a specific expression depending on tissue type. Their expression is often dysfunctional in many cancers, including LC, whereas they can play a biomarker role as they are released into blood circulation by the cancer cells. Interestingly, some mi-RNA may function as oncogenes or tumor suppressors genes [83] (Table 2).

\section{The role of NOTCH in LC}

It is a highly conserved developmental pathway that is significantly involved in tissue formation, cell differentiation and morphogenesis. Indications have shown that it plays an important role in several malignancies and can function as an oncogene or tumor suppressor gene depending on the cell type. Notch pathway is essential for the cell functions in tissues such as skin, pancreas and systems such central nervous, vascular, hematopoietic and muscular. In most tissues inhibits the initial cell differentiation by causing a second differentiation or by maintaining the cell in a non-undifferentiated status. It has been described as the guardian against differentiation [84].

The Notch family is transmembrane proteins that have dual function, as membrane receptors and as transcription factors. In mammals, the Notch family has 4 receptors and 5 ligands for those receptors, Delta $1,3,4$ and Jagged 1 and 2. When a ligand binds to its receptor, the pathway is activated and TACE metalloproteinase (tumor necrosis factor a converting enzyme) and the $\gamma$-secretase complex degrade the receptor by proteolysis. The part of the receptor derived from the activity of $\gamma$-secretase releases the intracellular part of Notch (NICD) 
Table 1. Signaling pathways and main types of genes involved in LC

\begin{tabular}{|c|c|c|c|}
\hline Cell Signaling Pathway & $\begin{array}{l}\text { Adenocarcinoma } \\
\text { Genes involved (\%) }\end{array}$ & $\begin{array}{l}\text { Squamous Carcinoma } \\
\text { Genes involved (\%) }\end{array}$ & $\begin{array}{l}\text { Small Cell Carcinoma } \\
\text { Genes involved (\%) }\end{array}$ \\
\hline TP53 & $\begin{array}{c}50 \\
\mathrm{P} 53, \mathrm{MDM} 2\end{array}$ & $\begin{array}{c}80 \\
\text { TP53 }\end{array}$ & $\begin{array}{l}80-90 \\
\text { TP53 }\end{array}$ \\
\hline RAS/RAF & $\begin{array}{c}25 \\
\text { KRAS, NF1, BRAF, NRAS }\end{array}$ & $\begin{array}{c}22 \\
\text { NF1, KRAS, HRAS, NRAS, RASA1, BRAF }\end{array}$ & \\
\hline PI3K/AKT & $\begin{array}{c}10-12 \\
\text { PIK3CA, PTEN, AKT1 }\end{array}$ & $\begin{array}{c}59 \\
\text { PIK3CA, PTEN, AKT1-3, TSC1-2 }\end{array}$ & $\begin{array}{c}10 \\
\text { PTEN }\end{array}$ \\
\hline MYC & $\begin{array}{c}30 \\
\text { MYC }\end{array}$ & & $\begin{array}{c}16-30 \\
\text { MYC, MYCN, MYCL }\end{array}$ \\
\hline RTK & $\begin{array}{c}50 \\
\text { EGFR, ALK, RET, ERBB2, ROS, MET }\end{array}$ & $\begin{array}{c}27 \\
\text { EGFR, FGFR1-3, ERBB2/3, DDR2 }\end{array}$ & $\begin{array}{c}6 \\
\text { FGFR1 }\end{array}$ \\
\hline RB1/CDKNA2 & $\begin{array}{c}15-20 \\
\text { CDKNA2 }\end{array}$ & $\begin{array}{c}79 \\
\text { CDKNA2, RB1 }\end{array}$ & $\begin{array}{c}100 \\
\text { RB1, CCNE1 }\end{array}$ \\
\hline Epigenetic regulation & $\begin{array}{c}22 \\
\text { SMARCA4, ARID1A, SETD2 }\end{array}$ & $\begin{array}{c}20 \\
\text { MLL2 }\end{array}$ & $\begin{array}{c}19 \\
\text { EP300, MLL, CREBBP }\end{array}$ \\
\hline Response to oxidative stress & $\begin{array}{c}10 \\
\text { KEAP } 1\end{array}$ & KEAP1, CUL3, NRF2 & \\
\hline Developmental pathway & 20 NKX2.1/TTF1 & $\begin{array}{c}44 \\
\text { SOX2, NOTCH1/2, ASCL4,FOXP1, TP63 }\end{array}$ & $\begin{array}{c}20 \\
\text { EPHA7, SLIT2 }\end{array}$ \\
\hline
\end{tabular}

Table 2. The main somatic genetic alterations in LC

\begin{tabular}{|c|c|c|c|c|c|}
\hline Gene & Signaling Pathway & Aberration & Adenocarcinoma (\%) & Squamous Carcinoma (\%) & Small Cell Carcinoma (\%) \\
\hline EGFR & RTK & Mutation Amplification & $\begin{array}{l}20-30 \\
>20\end{array}$ & $\begin{array}{c}\text { Rare } \\
7\end{array}$ & \\
\hline ROS & RTK & Mutation & 1.5 & & \\
\hline MET & RTK & $\begin{array}{l}\text { Mutation, Amplification after } \\
\text { treatment with EGFR inhibitor }\end{array}$ & $\begin{array}{c}5 \\
20\end{array}$ & & \\
\hline ERBB2 & RTK & Mutation, Amplification & $\begin{array}{c}2-4 \\
5-10\end{array}$ & & \\
\hline ERBB3 & RTK & Mutation & & 2 & \\
\hline ALK & RTK & Fusion with EML4, etc. & $3-13$ & & \\
\hline RET & RTK & Translocation with KIF5B, etc. & $1-2$ & & \\
\hline FGFR1 & RTK & Amplification & $1-3$ & 22 & 6 \\
\hline IGF1R & RTK & Overexpression & & & 95 \\
\hline LKB1 & $\begin{array}{l}\text { LKB1/AM } \\
\text { PK }\end{array}$ & Mutation & $15-30$ & 2 & \\
\hline CDKNA2/p16INK4 & $\mathrm{RB} 1 / \mathrm{CDK}$ & Deletions, Silencing, Mutation & $>20$ & 72 & \\
\hline RB1 & $\mathrm{RB} 1 / \mathrm{CDK}$ & Mutation & Rare & 7 & 100 \\
\hline CCNE1 & $\mathrm{RB} 1 / \mathrm{CDK}$ & Gain of copy & 12 & & \\
\hline KRAS & RAS & Mutation & 30 & 5 & \\
\hline NF1 & RAS & Mutation & $8-10$ & 11 & \\
\hline HRAS & RAS & Mutation & & 3 & \\
\hline NRAS & RAS & Mutation & $<1$ & $<1$ & \\
\hline RASA1 & RAS & Mutation & & 4 & \\
\hline BRAF & RAF & Mutation & 6 & 4 & \\
\hline PIK3CA & PI3K & Mutation & Rare & 16 & \\
\hline PTEN & PI3K & Deletion & Rare & 8 & \\
\hline AKT1,2,3 & PI3K & & Rare & $\begin{array}{l}16 \text { (AKT3) } \\
20 \text { all genes }\end{array}$ & \\
\hline TSC1,2 & PI3K & & & 6 & \\
\hline TP53 & TP53 & Mutation, Gene copy number loss & $\begin{array}{l}50 \\
20\end{array}$ & 80 & 70 \\
\hline MDM2 & TP53 & Amplification & 20 & & \\
\hline MYC & Regulator of transcription & Amplification & 31 & Rare & 16 \\
\hline MYCN & Regulator of transcription & Amplification & & & \\
\hline MYCL & Regulator of transcription & Amplification & & & \\
\hline SOX2 & $\begin{array}{c}\text { Developmental } \\
\text { pathway }\end{array}$ & Amplification, Overexpression & & 21 & \\
\hline TP63 & Developmental pathway & $\begin{array}{l}\text { Amplification, } \\
\text { Overexpression }\end{array}$ & & 16 & \\
\hline NOTCH1 & Developmental pathway & Mutation & & 8 & \\
\hline NOTCH2 & Developmental pathway & Mutation & & 5 & \\
\hline
\end{tabular}


into the cytoplasm which then is transferred from the cytoplasm to the nucleus and activates the transcription of target genes. The main target genes of that signaling pathway are two families of transcription factors, Hes and Herp, whereas other target genes are Cyclin D1, p21, NF-kB, preTa, GATA3, NRAPP, c-Myc and Deltex1 [85].

Notch pathway controls several stages of cell differentiation in different tissues and may be involved in the development of different types of tumors. Several investigations have indicated that is associated with lung, ovarian, breast cancer and leukemias. It is also closely linked to the ras signaling pathway and its activation is possible a result of oncogenesis mediated by the ras pathway. Once the Notch pathway is activated by the ras pathway it can be inversely triggered the ras-rafmek-MAPK pathway that consists a part of ras signaling pathway [86].

Notch signaling pathway is also critical for normal embryonic development. Given that tumori- genesis and organogenesis share the same mechanisms it is supposed that the cell signaling path- ways that are associated with human development and growth such as Notch, Wnt and Hedgehog play a role in the development and proliferation of cancer cells. Highly aggressive cancer cells have shown that they have many features of embryonic stem cells and use the Notch signaling pathway for its survival [87].

Dysfunction of Notch pathway is associated with many types of cancer and it has been shown that may has an oncogenic or tumorsuppressive action, depending on the tissue or the location of the organ expressed. The way in which the activation of the pathway itself leads to two adverse effects in different cell types remains unknown. A possible interpretation for that paradoxical behavior is that the Notch pathway activates/inactivates specific genes depending on the cell type or the signaling pathways which are the ones that determine the final effect of the Notch pathway on the cell. In conclusion, this pathway plays a critical role in maintaining a balance in the cell proliferation, survival, apoptosis and differentiation that affect the development and function of many organs. Dysfunction of that pathway also prevents the differentiation and can lead to malignant transformation $[85,86]$.

Regarding the role of that signaling pathway in LC, its function can follow two models, the one that is related to the adjacent cells communication and its different evolution and the second that is associated with the autonomic activity of the Notch receptors. In NSCLC cells, it has been shown that Notch 3 promotes tumor growth [88].

Another study showed that Notch 1 is under expressed in NSCLC cases and the expression of the self-active Notch 1 in AC cells causes cell death. It is interesting that Notch1 under hypoxic conditions is overexposed, which is important for the survival of cells in LC patients and still shows that the concentration of oxygen determines the biological activity of Notch 1 in LC. A similar observation concerns the Notch 1 and 3 expression in the cell line A549 and SPC-1 of the AC. Overexpression of the Notch intracellular domain (NICD) inhibits the growth of the AC A549 cells in vitro by inducing cell cycle arrest and this leads to suppression of tumor growth [89-91].Those observations suggest that the Notch pathway may have a tumor suppressor activity in AC cells. By comparison, in SCLC cells Notch1 and 2 are under expressed, whereas its overexpression inhibits the development of cancer cells.

\section{Signaling pathways in LC \\ PI3-K/AKT/mTOR pathway}

Phosphoinositide-3-kinases (PI3Ks) are a family of lipid protein kinases that regulate cellular functions such as cell proliferation, survival, mobility, adhesion and differentiation. When PI3Ks are activated by RTKs and G-protein coupled- receptors translate signals from multiple growth factors and cytokines into intracellular signals by the formation of phospholipids that activate cationic effector pathways, including AKT (protein kinase B), a Ser/Thr protein kinase [10].

One of the main cationic effectors of the PI3-K/AKT pathway is mTOR (mammalian target of rapamycin), that phosphorylates and activates the ribosomal protein S6-kinase (S6K1) and the eukaryotic translation initiation factor $4 \mathrm{E}$-linked protein 1 (4EBP1-eukaryotic translation initiation factor $4 \mathrm{E}$-binding protein), that regulates the protein synthesis [92]. PTEN is a tumor suppressor gene and the major negative regulator of the above signaling path- way as antagonizes PI3K [93].

The PI3-K/AKT/mTOR pathway is disrupted in SCLC cells, as the tumor cells show active mutations in PI3K and PTEN [94]. AKT is phosphorylated in $70 \%$ of SCLC cases [62], whereas protein expression of mTOR and S6K1 and phosphorylated 4EBP1 are at elevated levels in SCLC cells compared to alveolar epithelial type II cells. Such alterations lead to tumor growth, survival and resistance to chemotherapy in SCLC cases [95].

\section{Developmental pathways}

Developmental pathways such as Hedgehog, Notch and Wnt that regulate the self-renewal of stem cells when they are abnormally activated, can cause a neoplastic proliferation, representing an early event in oncogenesis [96].

NSLC displays a characteristic neuroendocrine phenotype, expressing neuronal and endocrine markers, such as synaptophysin, chromogranin and CD-56 [91]. Neuroendocrine cells are the first recognizable differentiated cells in the airways epithelium during lung development [88].

Such differentiation of neuroendocrine cells from the underlying endoderm is regulated by the Notch pathway and abnormalities of those cells can lead to extend that cellular compartment. There is evidence that SCLC is the most undifferentiated epithelial tumor of the airways and its features are similar to the ones of the early formation of the lung [97]. SCLC development depends on abnormalities in Notch and activation of Hedgehog pathway. Targeting of those pathways can lead to the elimination of SCLC cloned cells and to more lasting effects of treatment [98].

Sonic Hedgehog pathway plays an essential role during early lung development and in epithelial- mesenchymal interactions $[99,100]$. Three well known ligands of that pathway in human organs have been described, Sonic Hedgehog (SHh), Indian Hedgehog (IHh) and Desert Hedgehog (DHh). The signal transduction cascade begins with the binding of $\mathrm{Hh}$ in the Pattched-1 receptor (Ptch-1), a transmembrane protein of 12 segments. In absence of Hh ligand, Ptch-1 inhibits the seven transmembrane proteins Smoothened (Smo) and leads to inactivation of that pathway. However, the connection of Hh to Ptch1 leads to the inhibition of Smo release and then a protein complex is activated and leads to downstream transcription of Hh target in the nucleus, including Gli-1and Ptch-1.The active Hedgehog pathway leads to the extension of an intra- epithelial cell population during the regeneration of the airways after injury [100]. Activation of the Hedgehog pathway in that intraepithelial cell population predominates directly in the development of the neuroendocrine cells of the airways [101]. In SCLC cases has been observed a ligand-dependent activation of the Hedgehog pathway, whereas the adjacent cells express $\mathrm{SHh}$ $[96,98,100]$. 
The Notch pathway regulates the growth and differentiation of cells in various frames $[10,102]$. The most important function is to maintain non differentiated pluripotent cells in tissues [103] and plays a critical role in regulation of the airway epithelium development and is especially involved in neuroendocrine or non-neuroendocrine cell differentiation [88].

Overexpression of Notch receptors cause cell cycle arrest and inhibit the development of SCLC. Therefore, activation of the Notch pathway could be an effective strategy for SCLC patients [91].

The Wnt pathway includes proteins, a family of secretory molecules with various types of expression and a series of functions such as cell proliferation, differentiation, survival, apoptosis and cell mobility [104]. Three Wnt signaling pathways have been characterized. The first is the normal signaling and is activated by binding $\mathrm{Fz}$ (Frizzled) ligand and LDL-protein-related receptor (LRP) and leads to stabilization of the cytosol and nuclear translocation of $\beta$-Catenin for target gene expression (Wnt/ $\beta$-Catenin pathway) [105]. The second pathway involves the activation of the calcium/calmodulin-dependent protein kinase II and protein kinase $\mathrm{C}$ which is a non-canonical pathway. The third pathway, known as non-canonical planar cell polarity path- way, acts through small GTP-ases such as RhoaA and Jun Kinase (JNK) and participates in re- arrangements of cytoskeleton and cell polarity [106].

During lung morphogenesis, is required a special Wnt signaling for normal epithelium- mesenchymal interactions. When the Wnt pathways are deregulated, poisonous effects can be appeared. In the adult lung all the components of Wnt signaling are present in detectable levels. Broncho-alveolar stem cells coexpress Clara and protein markers of epithelial cells are maintained and activated by the Wnt signaling[107]. When the bronchial cells are exposed to cigarette smoke, the Wnt pathway is activated and leads to proliferation and tumor growth [108]. In NSCLC samples, Wnt molecules are expressed differently by upregulation of Wnt proteins, such as Wnt 1 and 2, and decreased expression of Wnt modulators, such as WIF1 (Wnt inhibitory factor 1) [107].

\section{Intracellular molecule chaperones-heat shock protein (HSP-90)}

Heat shock proteins are a family of highly homologous chaperone proteins and are involved in protein maturation, proteins transposition along the membranes, proteins quality control in endoplasmic reticulum and normal protein mobility [109]. The Hsp-90 is an expressed cell protein, that is increased in tumor cells, under stress conditions due to the presence of mutant and deregulated proteins, oxidative damage, hypoxia or low nutrient environment [110].

Those proteins also include many oncogenic members such as AKT, MET, bcl-2, telomerase, survivin and Apaf-1, thereby can promote cell survival, growth and metastases as are able to allow for continuous protein translation and cell proliferation [111]. Thus, inhibition of Hsp90 may be influenced the function of the correspondence chaperone in those malignancies and transformed cells, leading to disruption of oncogenes and multiple signaling pathways [110]. In SCLC cases was observed an overexpression of anti-apoptotic proteins and decrease in pre- apoptotic molecules, leading to deregulation of apoptosis. Hsp-90 is a major inhibitor of apoptosis in SCLC cases and differs from other cellular systems [111]. Pre-clinical studies have shown that Hsp-90 inhibition in SCLC cells releases Apaf-1that can leads to the formation of the Apaf- 1 and caspase- 9 apoptotic complex. That complex causes significant apoptosis only after the activation by Cyt $\mathrm{C}$ that is released from mitochondria, and is activated by the simultaneous inactivation of AKT by the inhibition of Hsp-90. When the AKT is downgraded, the $\mathrm{BAD}$ is dephosphorylated. Then the BAD heterodimerizes with selective antiapoptotic Bcl-2 family members or activates pre-apoptotic Bax and Bak proteins causing mitochondrial depolarization [96,111]. It is obvious that Hsp-90 regulates apoptosis in SCLC cases as a negative regulator of Apaf-1 and by controlling survival pathways PI3K-AKT [111].

\section{References}

1. Hanahan D, Weinberg RA (2000) The hallmarks of cancer. Cell 100: 57-70. [Crossref]

2. WHO (1988) Histological typing of lung tumors. ( $2^{\text {nd }}$ Edtn). WHO, Geneva. Pp: 1-36.

3. Brambilla E, Gazdar A (2009) Pathogenesis of lung cancer signalling pathways: roadmap for therapies. Eur Respir J 33: 1485-1497. [Crossref]

4. Massion PP, Carbone DP (2003) The molecular basis of lung cancer: molecular abnormalities and therapeutic implications. Respir Res 4: 12. [Crossref]

5. Park IW, Wistuba II, Maitra A, Milchgrub S, Virmani AK, et al. (1999) Multiple clonal abnormalities in the bronchial epithelium of patients with lung cancer. $J$ Natl Cancer Inst 91: 1863-1868. [Crossref]

6. Geradts J, Fong KM, Zimmerman PV, Maynard R, Minna JD (1999) Correlation of abnormal RB, p16ink4a, and p53 expression with 3p loss of heterozygosity, other genetic abnormalities, and clinical features in 103 primary non-small cell lung cancers. Clin Cancer Res 5: 791-800. [Crossref]

7. Girard L, Zöchbauer-Müller S, Virmani AK, Gazdar AF, Minna JD (2000) Genomewide allelotyping of lung cancer identifies new regions of allelic loss, differences between small cell lung cancer and non-small cell lung cancer, and loci clustering. Cancer Res 60: 4894-4906. [Crossref]

8. Minna JD, Fong K, Zöchbauer-Müller S, Gazdar AF (2002) Molecular pathogenesis of lung cancer and potential translational applications. Cancer J 8 Suppl 1: S41-46. [Crossref]

9. Zochbauer-Muller S, Gazdar AF, Minna JD (2002) Molecular pathogenesis of lung cancer. Annu Rev Physiol 64: 681-708. [Crossref]

10. Fong KM, Sekido Y, Gazdar AF, Minna JD (2003) Lung cancer. 9: Molecular biology of lung cancer: clinical implications. Thorax 58: 892-900. [Crossref]

11. Sattler M, Salgia R (2003) Molecular and cellular biology of small cell lung cancer Semin Oncol 30: 57-71. [Crossref]

12. Balsara BR, Testa JR (2002) Chromosomal imbalances in human lung cancer Oncogene 21: 6877-6883. [Crossref]

13. Sato M, Shames DS, Gazdar AF, Minna JD (2007) A translational view of the molecular pathogenesis of lung cancer. $J$ Thorac Oncol 2: 327-343. [Crossref]

14. Burbee DG, Forgacs E, Zöchbauer-Müller S, Shivakumar L, Fong K, et al. (2001) Epigenetic inactivation of RASSF1A in lung and breast cancers and malignant phenotype suppression. J Natl Cancer Inst 93: 691-699. [Crossref]

15. Keum JS, Kong G, Yang SC, Shin DH, Park SS, et al. (1999) Cyclin D1 overexpression is an indicator of poor prognosis in resectable non-small cell lung cancer. Br J Cancer 81: 127-132. [Crossref]

16. Fukuse T, Hirata T, Naiki H, Hitomi S, Wada H (2000) Prognostic significance of cyclin E overexpression in resected non-small cell lung cancer. Cancer Res 60: 242244. [Crossref]

17. Soria JC, Jang SJ, Khuri FR, Hassan K, Liu D, et al. (2000) Overexpression of cyclin B1 in early-stage non-small cell lung cancer and its clinical implication. Cancer Res 60: 4000-4004. [Crossref]

18. Sibilia M, Kroismayr R, Lichtenberger BM, Natarajan A, Hecking M, et al. (2007) The epidermal growth factor receptor: from development to tumorigenesis. Differentiation 75: 770-787. [Crossref]

19. Danesi R, de Braud F, Fogli S, de Pas TM, Di Paolo A, et al. (2003) Pharmacogenetics of anticancer drug sensitivity in non-small cell lung cancer. Pharmacol Rev 55: 57-103. [Crossref]

20. Nicholson RI, Gee JM, Harper ME (2001) EGFR and cancer prognosis. Eur J Cancer 37 Suppl 4: S9-15. [Crossref]

21. Battey J, Moulding C, Taub R, Murphy W, Stewart T, et al. (1983) The human c-myc oncogene: structural consequences of translocation into the $\mathrm{IgH}$ locus in Burkitt lymphoma. Cell 34: 779-787. [Crossref] 
22. Meyerson M (2007) Cancer: broken genes in solid tumours. Nature 448: 545-546. [Crossref]

23. Krystal G, Birrer M, Way J, Nau M, Sausville E, et al. (1988) Multiple mechanisms for transcriptional regulation of the myc gene family in small-cell lung cancer. $\mathrm{Mol} \mathrm{Cell}$ Biol 8: 3373-3381. [Crossref]

24. Richardson GE, Johnson BE (1993) The biology of lung cancer. Semin Oncol 20: 105127. [Crossref]

25. Rom WN, Hay JG, Lee TC, Jiang Y, Tchou-Wong KM (2000) Molecular and genetic aspects of lung cancer. Am J Respir Crit Care Med 161: 1355-1367. [Crossref]

26. Forgacs E, Zöchbauer-Müller S, Oláh E, Minna JD (2001) Molecular genetic abnormalities in the pathogenesis of human lung cancer. Pathol Oncol Res 7: 6-13. [Crossref]

27. Johnson BE, Russell E, Simmons AM, Phelps R, Steinberg SM, et al. (1996) MYC family DNA amplification in 126 tumor cell lines from patients with small cell lung cancer. J Cell Biochem Suppl 24: 210-217. [Crossref]

28. Mascaux C, Iannino N, Martin B, Paesmans M, Berghmans T, et al. (2005) The role of RAS oncogene in survival of patients with lung cancer: a systematic review of the literature with meta-analysis. Br J Cancer 92: 131-139. [Crossref]

29. Mills NE, Fishman CL, Rom WN, Dubin N, Jacobson DR (1995) Increased prevalence of K-ras oncogene mutations in lung adenocarcinoma. Cancer Res 55: 1444-1447. [Crossref]

30. Graziano SL, Gamble GP, Newman NB, Abbott LZ, Rooney M, et al. (1999) Prognostic significance of K-ras codon 12 mutations in patients with resected stage I and II nonsmall-cell lung cancer. J Clin Oncol 17: 668-675. [Crossref]

31. Wistuba II, Behrens C, Virmani AK, Mele G, Milchgrub S, et al. (2000) High resolution chromosome $3 \mathrm{p}$ allelotyping of human lung cancer and preneoplastic/preinvasive bronchial epithelium reveals multiple, discontinuous sites of $3 p$ allele loss and three regions of frequent breakpoints. Cancer Res 60: 1949-1960. [Crossref]

32. Zabarovsky ER, Lerman MI, Minna JD (2002) Tumor suppressor genes on chromosome $3 p$ involved in the pathogenesis of lung and other cancers. Oncogene 21: 6915-6935. [Crossref]

33. Sard L, Accornero P, Tornielli S, Delia D, Bunone G, et al. (1999) The tumor-suppressor gene FHIT is involved in the regulation of apoptosis and in cell cycle control. Proc Natl Acad Sci U S A 96: 8489-8492. [Crossref]

34. Wistuba II, Gazdar AF, Minna JD (2001) Molecular genetics of small cell lung carcinoma. Semin Oncol 28: 3-13. [Crossref]

35. Virmani AK, Rathi A, Zöchbauer-Müller S, Sacchi N, Fukuyama Y, et al. (2000) Promoter methylation and silencing of the retinoic acid receptor-beta gene in lung carcinomas. J Natl Cancer Inst 92: 1303-1307. [Crossref]

36. Oren M (2003) Decision making by p53: life, death and cancer. Cell Death Differ 10 431-442. [Crossref]

37. Sekido Y, Fong KM, Minna JD (2003) Molecular genetics of lung cancer. Annu Rev Med 54: 73-87. [Crossref]

38. Modi S, Kubo A, Oie H, Coxon AB, Rehmatulla A, et al. (2000) Protein expression of the RB-related gene family and SV40 large T antigen in mesothelioma and lung cancer. Oncogene 19: 4632-4639. [Crossref]

39. Agathanggelou A, Cooper WN, Latif F (2005) Role of the Ras-association domain family 1 tumor suppressor gene in human cancers. Cancer Res 65: 3497-3508. [Crossref]

40. Ji L, Roth JA (2008) Tumor suppressor FUS1 signaling pathway. J Thorac Oncol 3: 327-330. [Crossref]

41. Schulze-Bergkamen H, Krammer PH (2004) Apoptosis in cancer--implications for therapy. Semin Oncol 31: 90-119. [Crossref]

42. Belka C, Budach W (2002) Anti-apoptotic Bcl-2 proteins: structure, function and relevance for radiation biology. Int J Radiat Biol 78: 643-658. [Crossref]

43. Reed JC (1997) Double identity for proteins of the Bcl-2 family. Nature 387: 773-776. [Crossref]

44. Cory S, Huang DC, Adams JM (2003) The Bcl-2 family: roles in cell survival and oncogenesis. Oncogene 22: 8590-8607. [Crossref]

45. Yip KW, Reed JC (2008) Bcl-2 family proteins and cancer. Oncogene 27: 6398-6406. [Crossref]

46. Haura EB, Cress WD, Chellappan S, Zheng Z, Bepler G (2004) Antiapoptotic signaling pathways in non-small-cell lung cancer: biology and therapeutic strategies. Clin Lung Cancer 6: 113-122. [Crossref]
47. Adams JM, Cory S (2007) The Bcl-2 apoptotic switch in cancer development and therapy. Oncogene 26: 1324-1337. [Crossref]

48. Kaiser U, Schilli M, Haag U, Neumann K, Kreipe H, et al. (1996) Expression of bcl-2-protein in small cell lung cancer. Lung Cancer 15: 31-40. [Crossref]

49. Martin B, Paesmans M, Berghmans T, Branle F, Ghisdal L, et al. (2003) Role of Bcl-2 as a prognostic factor for survival in lung cancer: a systematic review of the literature with meta-analysis. Br J Cancer 89: 55-64. [Crossref]

50. Stathopoulos GT, Sherrill TP, Cheng DS, Scoggins RM, Han W, et al. (2007) Epithelial NF-kappaB activation promotes urethane-induced lung carcinogenesis. Proc Natl Acad Sci U S A 104: 18514-18519. [Crossref]

51. Zakian VA (1995) Telomeres: beginning to understand the end. Science 270: 16011607. [Crossref]

52. Moyzis RK, Buckingham JM, Cram LS, Dani M, Deaven LL, et al. (1988) A highly conserved repetitive DNA sequence, (TTAGGG)n, present at the telomeres of human chromosomes. Proc Natl Acad Sci U S A 85: 6622-6626. [Crossref]

53. Harley CB, Futcher AB, Greider CW (1990) Telomeres shorten during ageing of human fibroblasts. Nature 345: 458-460. [Crossref]

54. Evans SK, Lundblad V (2000) Positive and negative regulation of telomerase access to the telomere. J Cell Sci 113 Pt 19: 3357-3364. [Crossref]

55. Holt SE, Shay JW (1999) Role of telomerase in cellular proliferation and cancer. J Cell Physiol 180: 10-18. [Crossref]

56. Yao Y, Choi J, Parker I (1995) Quantal puffs of intracellular Ca2+ evoked by inositol trisphosphate in Xenopus oocytes. J Physiol $482: 533-553$. [Crossref]

57. Hiyama K, Hiyama E, Ishioka S, Yamakido M, Inai K, et al. (1995) Telomerase activity in small-cell and non-small-cell lung cancers. J Natl Cancer Inst 87: 895-902. [Crossref]

58. Shay JW, Zou Y, Hiyama E, Wright WE (2001) Telomerase and cancer. Hum Mol Genet 10: 677-685. [Crossref]

59. Counter CM, Avilion AA, LeFeuvre CE, Stewart NG, Greider CW, et al. (1992) Telomere shortening associated with chromosome instability is arrested in immortal cells which express telomerase activity. EMBO J 11: 1921-1929. [Crossref]

60. Albanell J, Lonardo F, Rusch V, Engelhardt M, Langenfeld J, et al. (1997) High telomerase activity in primary lung cancers: association with increased cell proliferation rates and advanced pathologic stage. J Natl Cancer Inst 89: 1609-1615. [Crossref]

61. Hyer JD, Silvestri G (2000) Diagnosis and staging of lung cancer. Clin Chest Med 21: 95-106, viii-ix. [Crossref]

62. Lantuejoul S, Soria JC, Morat L, Lorimier P, Moro-Sibilot D, et al. (2005) Telomere shortening and telomerase reverse transcriptase expression in preinvasive bronchial lesions. Clin Cancer Res 11: 2074-2082. [Crossref]

63. Tanno S, Ohsaki Y, Nakanishi K, Toyoshima E, Kikuchi K (2004) Human small cell lung cancer cells express functional VEGF receptors, VEGFR-2 and VEGFR-3. Lung Cancer 46: 11-19. [Crossref]

64. Fischer B, Marinov M, Arcaro A (2007) Targeting receptor tyrosine kinase signalling in small cell lung cancer (SCLC): what have we learned so far? Cancer Treat Rev 33 391-406. [Crossref]

65. Fontanini G, Vignati S, Boldrini L, Chinè S, Silvestri V, et al. (1997) Vascular endothelia growth factor is associated with neovascularization and influences progression of nonsmall cell lung carcinoma. Clin Cancer Res 3: 861-865. [Crossref]

66. Ruotsalainen T, Joensuu H, Mattson K, Salven P (2002) High pretreatment serum concentration of basic fibroblast growth factor is a predictor of poor prognosis in smal cell lung cancer. Cancer Epidemiol Biomarkers Prev 11: 1492-1495. [Crossref]

67. Pardo OE, Arcaro A, Salerno G, Tetley TD, Valovka T, et al. (2001) Novel cross talk between MEK and S6K2 in FGF-2 induced proliferation of SCLC cells. Oncogene 20: 7658-7667. [Crossref]

68. Pardo OE, Wellbrock C, Khanzada UK, Aubert M, Arozarena I, et al. (2006) FGF2 protects small cell lung cancer cells from apoptosis through a complex involving PKCepsilon, B-Raf and S6K2. EMBO J 25: 3078-3088. [Crossref]

69. Christofori G, Semb H (1999) The role of the cell-adhesion molecule E-cadherin as a tumour-suppressor gene. Trends Biochem Sci 24: 73-76. [Crossref]

70. Peaina-Slaus N (2003) Tumor suppressor gene E-cadherin and its role in normal and malignant cells. Cancer Cell Int 3: 17. [Crossref] 
71. Ohira T, Gemmill RM, Ferguson K, Kusy S, Roche J, et al. (2003) WNT7a induces E-cadherin in lung cancer cells. Proc Natl Acad Sci U S A 100: 10429-10434. [Crossref]

72. Bonomi P (2002) Matrix metalloproteinases and matrix metalloproteinase inhibitors in lung cancer. Semin Oncol 29: 78-86. [Crossref]

73. Shih JY, Yang SC, Hong TM, Yuan A, Chen JJ, et al. (2001) Collapsin response mediator protein-1 and the invasion and metastasis of cancer cells. $J$ Natl Cancer Inst 93: 1392-1400. [Crossref]

74. Raper JA (2000) Semaphorins and their receptors in vertebrates and invertebrates. Curr Opin Neurobiol 10: 88-94. [Crossref]

75. Akashi T, Ito E, Eishi Y, Koike M, Nakamura K, et al. (2001) Reduced expression of laminin alpha 3 and alpha 5 chains in non-small cell lung cancers. Jpn J Cancer Res 92: 293-301. [Crossref]

76. Miller YE (2005) Pathogenesis of lung cancer: 100 year report. Am J Respir Cell Mol Biol 33: 216-223. [Crossref]

77. Manda R, Kohno T, Niki T, Yamada T, Takenoshita S, et al. (2000) Differential expression of the LAMB3 and LAMC2 genes between small cell and non-small cell lung carcinomas. Biochem Biophys Res Commun 275: 440-445. [Crossref]

78. Park GH, Plummer HK 3rd, Krystal GW (1998) Selective Sp1 binding is critical for maximal activity of the human c-kit promoter. Blood 92: 4138-4149. [Crossref]

79. Ma PC, Kijima T, Maulik G, Fox EA, Sattler M, et al. (2003) c-MET mutational analysis in small cell lung cancer: novel juxtamembrane domain mutations regulating cytoskeletal functions. Cancer Res 63: 6272-6281. [Crossref]

80. Maulik G, Kijima T, Ma PC, Ghosh SK, Lin J, et al. (2002) Modulation of the c-Met/ hepatocyte growth factor pathway in small cell lung cancer. Clin Cancer Res 8: 620627. [Crossref]

81. Bikfalvi A, Klein S, Pintucci G, Rifkin DB (1997) Biological roles of fibroblast growth factor-2. Endocr Rev 18: 26-45. [Crossref]

82. Esteller M (2008) Epigenetics in cancer. N Engl J Med 358: 1148-1159. [Crossref]

83. Cowland JB, Hother C, Grønbaek K (2007) MicroRNAs and cancer. APMIS 115: 10901106. [Crossref]

84. Hansson EM, Lendahl U, Chapman G (2004) Notch signaling in development and disease. Semin Cancer Biol 14: 320-328. [Crossref]

85. Miele L (2006) Notch signaling. Clin Cancer Res 12: 1074-1079. [Crossref]

86. Kopan R, Ilagan MX (2009) The canonical Notch signaling pathway: unfolding the activation mechanism. Cell 137: 216-233. [Crossref]

87. Wang Z, Li Y, Banerjee S, Sarkar FH (2009) Emerging role of Notch in stem cells and cancer. Cancer Lett 279: 8-12. [Crossref]

88. Collins BJ, Kleeberger W, Ball DW (2004) Notch in lung development and lung cancer. Semin Cancer Biol 14: 357-364. [Crossref]

89. Chen Y, De Marco MA, Graziani I, Gazdar AF, Strack PR, et al. (2007) Oxygen concentration determines the biological effects of NOTCH-1 signaling in adenocarcinoma of the lung. Cancer Res 67: 7954-7959. [Crossref]

90. Zheng Q, Qin H, Zhang H, Li J, Hou L, et al. (2007) Notch signaling inhibits growth of the human lung adenocarcinoma cell line A549. Oncol Rep 17: 847-852. [Crossref]

91. Sriuranpong V, Borges MW, Ravi RK, Arnold DR, Nelkin BD, et al. (2001) Notch signaling induces cell cycle arrest in small cell lung cancer cells. Cancer Res 61:32003205. [Crossref]
92. Pal SK, Figlin RA, Reckamp KL (2008) The role of targeting mammalian target of rapamycin in lung cancer. Clin Lung Cancer 9: 340-345. [Crossref]

93. Liu P, Cheng H, Roberts TM, Zhao JJ (2009) Targeting the phosphoinositide 3-kinase pathway in cancer. Nat Rev Drug Discov 8: 627-644. [Crossref]

94. Krystal GW, Sulanke G, Litz J (2002) Inhibition of phosphatidylinositol 3-kinase-Akt signaling blocks growth, promotes apoptosis, and enhances sensitivity of small cell lung cancer cells to chemotherapy. Mol Cancer Ther 1: 913-922. [Crossref]

95. Marinov M, Ziogas A, Pardo OE, Tan LT, Dhillon T, et al. (2009) AKT/mTOR pathway activation and BCL-2 family proteins modulate the sensitivity of human small cell lung cancer cells to RAD001. Clin Cancer Res 15: 1277-1287. [Crossref]

96. Shimamura T, Shapiro GI (2008) Heat shock protein 90 inhibition in lung cancer. $J$ Thorac Oncol 3: S152-159. [Crossref]

97. Liu H, Kho AT, Kohane IS, Sun Y (2006) Predicting survival within the lung cancer histopathological hierarchy using a multi-scale genomic model of development. PLoS Med 3: e232. [Crossref]

98. Watkins DN, Berman DM, Baylin SB (2003) Hedgehog signaling: progenitor phenotype in small-cell lung cancer. Cell Cycle 2: 196-198. [Crossref]

99. Peacock CD, Watkins DN (2008) Cancer stem cells and the ontogeny of lung cancer. $J$ Clin Oncol 26: 2883-2889. [Crossref]

00. Watkins DN, Berman DM, Burkholder SG, Wang B, Beachy PA, et al. (2003) Hedgehog signalling within airway epithelial progenitors and in small-cell lung cancer. Nature 422: 313-317. [Crossref]

101. Kunnimalaiyaan M, Chen H (2007) Tumor suppressor role of Notch-1 signaling in neuroendocrine tumors. Oncologist 12: 535-542. [Crossref]

102. Lewis J (1998) Notch signalling and the control of cell fate choices in vertebrates. Semin Cell Dev Biol 9: 583-589. [Crossref]

103. Weinmaster G1 (1997) The ins and outs of notch signaling. Mol Cell Neurosci 9 : 91-102. [Crossref]

104. He B, Jablons DM (2006) Wnt signaling in stem cells and lung cancer. Ernst Schering Found Symp Proc : 27-58. [Crossref]

105. Akiyama T (2000) Wnt/beta-catenin signaling. Cytokine Growth Factor Rev 11: 273 282. [Crossref]

106. Veeman MT, Axelrod JD, Moon RT (2003) A second canon. Functions and mechanisms of beta-catenin-independent Wnt signaling. Dev Cell 5: 367-377. [Crossref]

107. Königshoff M1, Eickelberg O (2010) WNT signaling in lung disease: a failure or a regeneration signal? Am J Respir Cell Mol Biol 42: 21-31. [Crossref]

108. Lemjabbar-Alaoui H1, Dasari V, Sidhu SS, Mengistab A, Finkbeiner W, et al. (2006) Wnt and Hedgehog are critical mediators of cigarette smoke-induced lung cancer. PLoS One 1: e93. [Crossref]

109. Pratt WB (1998) The hsp90-based chaperone system: involvement in signa transduction from a variety of hormone and growth factor receptors. Proc Soc Exp Biol Med 217: 420-434. [Crossref]

110. Chiosis G, Vilenchik M, Kim J, Solit D (2004) Hsp90: the vulnerable chaperone Drug Discov Today 9: 881-888. [Crossref]

111. Rodina A, Vilenchik M, Moulick K, Aguirre J, Kim J, et al. (2007) Selective compounds define Hsp90 as a major inhibitor of apoptosis in small-cell lung cancer. Nat Chem Biol 3: 498-507. [Crossref]

Copyright: (C2018 Chrysanthakopoulos NA. This is an open-access article distributed under the terms of the Creative Commons Attribution License, which permits unrestricted use, distribution, and reproduction in any medium, provided the original author and source are credited. 